\title{
Comparison of Hypervariable Region (HVR) of mecA Gene in Staphylococcus aureus Isolated From Nasal Carriers and Clinical Samples
}

\author{
Neda Zeinali Nia ${ }^{1}$, Mohammad Reza Pourmand ${ }^{1,}$, , Parviz Afrough ${ }^{1}$ \\ ${ }^{1}$ Department of Pathobiology, School of Public Health, Tehran University of Medical Sciences, Tehran, IR Iran \\ *Corresponding author: Mohammad Reza Pourmand, School of Public Health and Biotechnology Research Center, Tehran University of Medical Sciences, Tehran, IR Iran. Tel: +98- \\ 2188954910, Fax:+98-2188954910, E-mail: mpourmand@tums.ac.ir.
}

Received: August 12, 2012; Revised: October 28, 2012; Accepted: January 12, 2013

\begin{abstract}
Background: Methicillin Resistant Staphylococcus aureus (MRSA) is a common major human pathogen that causes hospital-acquired infections. Characterization and typing of the staphylococcal cassette chromosome has led to a better understanding of MRSA infection cycle in hospital. The mecA-associated hypervariable region size classifies MRSA isolates that colonized in nasal carriers.

Objectives:The aim of this study was to compare the genetic background of hypervariable region (HVR) of mecA gene in S. aureus isolated from nasal carriers and clinical samples.

Materials and Methods: A cross sectional study was performed on 261 nasal swabs collected from healthy health care workers (HCW) and 109 clinical samples from Tehran university hospitals. All the S. aureus isolates were identified by biochemical tests (Coagulase, Catalase, Manitol fermentation, and DNase tests). S. aureus isolates were investigated for the variability of HVR of mecA gene by PCR method.

Results: Among 261 collected nasal swabs, 70 (27\%) were S. aureus. Of these, 29(41\%) isolates were resistant to Oxacillin and 32 (46\%) of those had mec-HVR gene. The polymerase chain reaction (PCR) products showed five different patterns of HVR. Also among 109 clinical samples, 52 (48\%) of them were S. aureus. Of these, 40 (77\%) were resistant to Oxacillin and 45 (87\%) of them carried the mec-HVR gene. The PCR products showed 11 different patterns of HVR.

Conclusions: Molecular typing of MRSA isolates by HVR amplification has shown a high diversity among the strains and can be used as a basis for tracking the contaminations and the source of hospital infections from staff to patients and vice versa.
\end{abstract}

Keywords: Staphylococcus aureus; Carrier State; Cross Infection

\section{Background}

Staphylococcus aureus is one of the most frequent human pathogens that produces a wide range of infections (1). The pathogen is resistant to most of common antibiotics and thus has caused many problems in treatment of diseases. A notable example in this regard is the emergence of Methicillin resistant S. aureus (MRSA), which was reported for the first time just one year after the introduction of Methicillin to the clinical practice. MRSA is an important hospital pathogen, and is responsible for development of various infections such as skin and soft tissue infections, pneumonia, bacteremia and catheterrelated infections $(2,3)$.

Resistance against Methicillin in S. aureus is due to a large mobile genetic element, called Staphylococcus cassette chromosome mec (SCCmec). The 20 - $50 \mathrm{~kb}$ region of mec DNA contains mecA gene, which encodes modified Penicillin binding protein (PBP2A) with lower affinity to beta-lactam antibiotics (4). The genomic distance of mecA and IS431 (insertion sequence 431) is very variable and is called the hypervariable region (HVR), which is consisted of exact repeated units of the $40 \mathrm{bp}$ length. The variability of the region is due to the high polymorphism observed in isolates of $S$. aureus $(4,5)$. The adjunct IS sequences, transposones, and the mec DNA can be considered as the hot spots, which include the antibiotic resistance genes (6).

It seems that the staphylococcal carriers play an important role in pathogenesis of the infections caused by $S$. aureus. The asymptomatic colonized patients and hospital staff are the main sources of MRSA in hospital environment. Health care workers (HCW) are considered as the link between patients. Screening of the carriers of MRSA is necessary for control of nosocomial infections (7).

The risk of carrier colonization with this pathogen and infections in diabetic patients, IV drug abusers, hemodialysis and surgical patients, and those with immune system deficiency are noteworthy. Considering the genetic variation of MRSA and the high rate of mortality of the patients and the high costs of treatment of the infections, the control of these infections should be accompanied with molecular typing methods. An ideal molecular technique should be rapid, easy to perform, and interpret. Moreover, the test should have a reasonable differentia-

Implication for health policy/practice/research/medical education:

Staphylococcus aureus persists in nasal canal of hospital health workers and can be transferred to the hospitalized patients. Determination of nasal colonized MRSA and clinical isolates based on mecA gene variation might be useful to investigate the cycle of infections in patients and health care workers. Copyright (C) 2013, Ahvaz JundishapurUniversity of Medical Sciences; Published by Kowsar Corp. This is an open-access article distributed under the terms of the Creative Commons Attribution License, which permits unrestricted use, distribution, and reproduction in any medium, provided the original work is properly cited. 
tion ability and repeatability (8). PCR based methods that are related to gene variation are currently highlighted. One of these methods is the amplification of HVR using PCR method.

\section{Objectives}

The aim of the study was to evaluate the genetic pattern of $S$. aureus isolated from hospital carriers, and comparing them with clinical specimens using HVR PCR amplification.

\section{Materials and Methods}

\subsection{Sample Collection and S. aureus Identification}

Collectively 261 nasal swabs of healthy HCW and 109 clinical samples were obtained from five Tehran University of Medical Sciences hospitals (I, II, III, IV, V) and (IV, $\mathrm{V})$, respectively. The samples were transferred to microbiology laboratory of School of Public Health and sub- cultured on $(5 \%)$ blood agar at $37^{\circ} \mathrm{C}$ overnight. Then all of the $S$. aureus isolates were confirmed by biochemical tests (Coagulase, Catalase, Manitol fermentation on Manitol salt agar culture and DNase tests) (9).

\subsection{Antibiotic Susceptibility}

Susceptibility to antibiotic was determined by using agar disc diffusion method on Muller Hinton agar medium containing (2\%) $\mathrm{NaCl}$, and Oxacillin disc (MAST, UK) and all plates were incubated at $35^{\circ} \mathrm{C}$ overnight (10).

\subsection{Genotype Analysis}

\subsubsection{DNA Extraction}

DNA was isolated by using genomic DNA extraction kit (Bioneer Inc., South Korea) as recommended by the manufacture, with the modification that $5 \mathrm{mM} 1.5 \lambda$ lysostaphin was added to bacterial suspension. Finally the genomic DNA extraction was used as the template for PCR.

\begin{tabular}{|c|c|c|c|}
\hline Hospital No. of HCWs ${ }^{a}$ & S. aureus Nasal Isolates, No. (\%) & $\begin{array}{l}\text { HVR Variability Based on Hospi- } \\
\text { tal Wards }{ }^{b}\end{array}$ & Oxacillin Resistance, No. (\%) \\
\hline \multirow[t]{5}{*}{$I(n=43)$} & $14(31.8)$ & & $5(35.7)$ \\
\hline & & H1: [1] (Internal) & \\
\hline & & H2: [2] (Internal) & \\
\hline & & H6:[3] (Internal) & \\
\hline & & H10:[1] (Internal) & \\
\hline \multirow[t]{3}{*}{ II $(\mathbf{n}=70)$} & $19(27.1)$ & & $5(26.3)$ \\
\hline & & H5: [2] (Orthopedic) & \\
\hline & & $\begin{array}{l}\text { H6: [2] (Orthopedic), [1] (Emer- } \\
\text { gency) }\end{array}$ & \\
\hline \multirow[t]{4}{*}{ III $(\mathbf{n}=79)$} & $15(19)$ & & \\
\hline & & H1: [1] (Neurology); & \\
\hline & & H5: [2] (Surgery) & \\
\hline & & $\begin{array}{l}\text { H6:[1](Surgery),[1] (Dialysis),[1] } \\
\text { (Neurology) }\end{array}$ & $6(40)$ \\
\hline \multirow[t]{3}{*}{$\operatorname{IV}(\mathbf{n}=\mathbf{3 4})$} & $9(26.5)$ & & \\
\hline & & H5: [2] (Internal) & \\
\hline & & H6:[2](Neurology) & \\
\hline \multirow[t]{2}{*}{$V(n=35)$} & $13(37.1)$ & $\begin{array}{l}\mathrm{H} 5:[2] \text { (Dialysis), [2] (ICU) }{ }^{\mathrm{a}},[2] \\
\text { (Transplant) }\end{array}$ & \\
\hline & & H6: [2] (ICU), [2] (Transplant) & \\
\hline Total $(\mathbf{n}=\mathbf{2 6 1})$ & $70(26.8)$ & 32 & \\
\hline
\end{tabular}

\subsubsection{PCR Analysis}

A collection of $S$. aureus isolates, were screened for the presence of HVR mecA gene. The following primers were used to amplify fragments of mobile elements associated with the mecA region (11).
HVR1: (5'-ACT ATT CCC TCA GGC GTC C-3') HVR2: (5'-GGA GTT AAT CTA CGT CTC ATC-3')

In this study $S$. aureus strain COL (a fully sequenced MRSA strains) was used as positive control and distilled 
water as a negative control for PCR. PCR reaction was performed in Ependorf thermocycler at a final volume of 50 $\mu \mathrm{L}$ containing, $10 \mu \mathrm{L}$ of $10 x$ PCR Buffer, $3 \mu \mathrm{L}$ of $\mathrm{MgCL}_{2}(10$ $\mathrm{mM}$ ), $0.2 \mathrm{mM}$ dNTP mix, $20 \rho \mathrm{M}$ of each primer, $1 \mathrm{U}$ of Taq polymerase and $4 \mu \mathrm{L}$ of template DNA.

Amplification was carried out as follow: denaturation at $94^{\circ} \mathrm{C}$ for 3 minutes (first denaturation) and repeated in 30 cycles according to the following program: denaturation at $94^{\circ} \mathrm{C}$ for 45 seconds, annealing at $55^{\circ} \mathrm{C}$ for 30 seconds and extension at $72^{\circ} \mathrm{C}$ for 90 seconds and the final extension at $72{ }^{\circ} \mathrm{C}$ for 10 minutes to complete partial polymerization (11).

\section{Results}

In this study on $261 \mathrm{HCW}$ nasal swab samples, 70 (27\%) were found to be $S$. aureus . Of these, 29 (41\%) were MRSA and 32 (46\%) had mec- HVR gene. The proportion of MRSA among nasal carriers isolates from different hospitals varied from $26 \%$ to $62 \%$. The highest incidence of $S$. aureus belonged to $\mathrm{V}$ hospital (37.1\%) and also the highest incidence of MRSA belonged to that hospital (61.5\%). Molecular typing of the $70 \mathrm{~S}$. aureus from nasal carrier isolates by HVR-PCR illustrated five HVR types: HVR 1 (350 bp), HVR 2 (400 bp), HVR 5 (550 bp), HVR 6 (600 bp) and HVR 10 (800 bp). The hospital wards that these types obtained were internal, orthopedic, emergency, surgery, dialysis, neurology, ICU, and transplantation wards (Table 1).

Different HVR types obtained from eight mentioned wards collected from nasal carriers has been distributed, Internal $(1,2,5,6,10)$, Orthopedic $(5,6)$, Emergency (6), Neurology $(2,6)$, Surgery $(5,6)$, Dialysis $(5,6)$, Transplant $(5,6)$ and ICU $(5,6)$. The greater variations of HVR types were found in internal ward $(1,2,5,6,10)$ (Table 1$)$.

Also among 109 clinical samples collected from patients of two hospitals, 52 (47.7\%) were S. aureus . Of these, 40 isolates (77\%) were MRSA and 45 isolates (87\%) have mec- HVR gene. The highest incidence of $S$. aureus collected from $\mathrm{V}$ hospital (83.3\%) and also the highest proportion of MRSA was also detected in this hospital (Table 2).

\begin{tabular}{|c|c|c|c|}
\hline Hospital No. of HCWs ${ }^{\text {a }}$ & S. aureus Nasal Isolates, No. (\%) & HVR Variability Based on Hospital Wards ${ }^{b}$ & Oxacillin Resistance, No. (\%) \\
\hline \multirow[t]{10}{*}{ IV (56) } & $22(39.2)$ & & $15(68.2)$ \\
\hline & & H2: [2] (Neurology) & \\
\hline & & H3: [1] (NICU) ${ }^{\mathrm{b}},[1](\mathrm{PICU})^{\mathrm{c}}$ & \\
\hline & & H4: [1] (PICU) & \\
\hline & & $\mathrm{H} 5:[1](\mathrm{NICU})$ & \\
\hline & & H6: [1] (NICU) & \\
\hline & & H7: [2] (PICU); H8: [1](NICU), [1] (Internal) & \\
\hline & & H9: [1](PICU),[1](NICU), [1] (Internal ) & \\
\hline & & H10:[2](PICU), [2] (NICU) & \\
\hline & & H11: [2](PICU) & \\
\hline \multirow[t]{9}{*}{$V(53)$} & $30(56.6)$ & & $25(83.3)$ \\
\hline & & $\begin{array}{l}\text { H1: [1] (Surgery); H4: [1] (ICU), ,[1] (Neurol- } \\
\text { ogy) }\end{array}$ & \\
\hline & & H5: [2] (ICU), [1] (Emergency), [1] (Surgery) & \\
\hline & & H6:[2] (ICU) & \\
\hline & & H7: [1] (Neurology) & \\
\hline & & H8: [1] (ICU), [1] (Emergency) & \\
\hline & & $\begin{array}{l}\text { H9: [1] (Orthopedic), [1] (ICU), [1] (Emer- } \\
\text { gency) }\end{array}$ & \\
\hline & & $\begin{array}{l}\text { H10: [4] (ICU), [2] (Surgery), [2] (Orthope- } \\
\text { dic) }\end{array}$ & \\
\hline & & $\begin{array}{l}\text { H11: [2] (Orthopedic), [1] (ICU), [1] (Endocri- } \\
\text { nology) }\end{array}$ & \\
\hline Total (109) & $52(47.7)$ & 45 & $40(76.9)$ \\
\hline
\end{tabular}

\footnotetext{
a Abbreviations: HCW, health care workers; NICU, Neonatal Intensive Care Unit; PICU, Pediatric Intensive Care Unit

$\mathrm{b}_{\text {Number of HVR type }}$
} 
Molecular typing of 52 S. aureus from clinical isolates by HVR-PCR method have demonstrated the presents of HVR in HVR types. In addition of the types which has been observed in nasal carriers, the types HVR 3 (450 bp), HVR 4 (500 bp), HVR 7 (650 bp), HVR 8 (700 bp), HVR 9 (750 bp) and HVR 11 ( $850 \mathrm{bp}$ ) only are conspicuous in clinical isolates. The hospital wards which these types obtained were surgery, orthopedic, emergency, neurology, ICU, endocrinology, PICU and NICU. Distribution of different HVR types collected from nine wards were as follow: Surgery $(1,5,10)$, ICU $(4,5,6,8,9,10,11)$, Neurology $(4,7,2)$, Emergency (5, 9), Orthopedic $(9,10,11)$, Endocrinology (11), NICU $(3,5,6,9,10), \operatorname{PICU}(3,4,7,9,10,11)$ and Internal $(8,9)$ (Table 2$)$. The variation of HVR types in collected isolated from intensive care units (ICUS) was higher than other wards of hospital.

\section{Discussion}

In the current study, 70 and 52 isolates of $S$. aureus were evaluated by detecting the HVR of mecA in isolates collected from HCW and patients, respectively. Amplification of HVR by PCR resulted in identification of 5 and 11 types in carriers and patients, respectively. In a similar study on typing of clinical isolates of MRSA, 72 isolates were classified according to the results of HVR typing (12). Moreover, seven HVR types were identified, two of which were common in the species of pandemic MRSA and one type had a high prevalence in sporadic species (12).

The HVR typing method was used in another study to type the MRSA isolates obtained from clinical specimens. The primers were similar to those we used in the current study. In the study, four types of HVR ( $451 \mathrm{bp}, 491 \mathrm{bp}, 571$ $\mathrm{bp}$, and $611 \mathrm{bp}$ ) were reported, which were close to types $3,4,5$, and 6 in our study (6). In another study, by using six classification methods including HVR typing, 183 clinical isolates of MRSA in five HVR types of 400, 450, 500, 550, and $600 \mathrm{bp}$, which were corresponding to types 2, 3, 4, 5, and 6 were classified (11). Types 2, 5 and 6 were recognized in carriers, while types $2,3,4,5$ and 6 were observed in patients. A notable finding was that the highest prevalence and varieties of MRSA types was detected in samples collected from ICU wards.

Considering the above mentioned findings, it can be concluded that typing the clinical isolates of MRSA based on HVR amplification has a higher diversity in our country and can be used as a basis for tracking the contaminations and the source of hospital infections from staff to patients and vice versa (as a cycle). For instance, HVR 5 and 6 types in the current study were isolated from 13 and 12 samples, respectively, both from the carriers and patients. Furthermore, the types 5 and 6 isolated from ICU wards were similar in carriers and patients. These two types were isolated from samples taken from the ICU patients and also the staff working in ICU wards. These types may be circulated in the ward and transmitted from staff to patients and vice versa.
It should be noted that HVR 6 (600 bp) was the most frequent type in all hospitals under evaluation. Also, the type collected from hospital staff with working history of six months to ten years and it seems that the type has a high colonization capability.

The typing of pathogens isolated from carriers using HVR typing method was not observed in similar studies. Also, the number of isolated types from the carriers was less than half of the number of HVR types isolated from the patients. Out of $70 \mathrm{~S}$. aureus samples collected from the carriers, 32 samples were positive for mec-HVR and 29 samples were resistant against Methicillin. The results indicated that when the isolates are phenotypically Methicillin resistant, genotypically they are positive for mecA gene. This is while some sensitive isolates also have mecA gene. The underlying cause of this discrepancy between phenotype and genotype can be pointed the mutations, which leads to palindrome defect in -10 region of mecA promoter (13).

Moreover, it was mentioned that the clinical isolates from the ICU wards had shown the highest number of HVR types. The ICU wards, which also include NICU and PICU, are probably appropriate places for epidemic outbreaks of the infections. The highest prevalence of $S$. aureus and MRSA among the patients was observed in V hospital. It was observed that HVR 10 (800 bp) was circulating among the patients hospitalized in ICU ward of V hospital. The lowest number of isolates was detected in both patients and carriers patients in dialysis and transplantation wards in all hospital. In a study carried out in Switzerland HVR typing mentioned as a useful method for exploration of the infection outbreak source, since it has a high specify and in comparison with other typing methods such as PFGE, this is a rapid and inexpensive method (14).

In conclusion, S. aureus exists in nares of HCW and can be transferred to the hospitalized patients. Detection of MRSA nasal colonization and clinical isolates based on mecA gene variation might be useful for investigation the cycle of infections among patients and health care workers who are continuously and directly in contact with patients. Therefore, the study confirms the significant effect of detecting the carriers, treating and decolonizing them in order to take proper treatment measures and prevent their transmission, mortality and diseases progress.

\section{Acknowledgements}

There is no Acknowledgments.

\section{Authors' Contribution}

None declared.

\section{Financial Disclosure}

There is no Financial Disclosure. 


\section{Funding/Support}

This research has been supported by Tehran University of Medical Sciences Grant No: 9805.

\section{References}

1. Gordon RJ, Lowy FD. Pathogenesis of methicillin-resistant Staphylococcus aureus infection. Clin Infect Dis. 2008;46(5):S350-9.

2. Havaei S, Moghadam SO, Pourmand M, Faghri J. Prevalence of Genes Encoding Bi-Component Leukocidins among Clinical Isolates of Methicillin Resistant Staphylococcus aureus. Iran J Public Health. 2010;39(1):8-14.

3. Pourmand MR, Memariani M, Hoseini M, Yazdchi SB. High prevalence of sea gene among clinical isolates of Staphylococcus aureus in Tehran. Acta Medica Iranica. 2009;47(5).

4. Heusser R, Ender M, Berger-Bachi B, McCallum N. Mosaic staphylococcal cassette chromosome mec containing two recombinase loci and a new mec complex, B2. Antimicrob Agents Chemother. 2007;51(1):390-3.

5. Ryffel C, Bucher R, Kayser FH, Berger-Bachi B. The Staphylococcus aureus mec determinant comprises an unusual cluster of direct repeats and codes for a gene product similar to the Escherichia coli sn-glycerophosphoryl diester phosphodiesterase. J Bacteriol. 1991;173(23):7416-22.

6. Senna JP, Pinto CA, Carvalho LP, Santos DS. Comparison of pulsedfield gel electrophoresis and PCR analysis of polymorphisms on the mec hypervariable region for typing methicillin-resistant Staphylococcus aureus. J Clin Microbiol. 2002;40(6):2254-6.

7. Mathanraj S, Sujatha S, Sivasangeetha K, Parija SC. Screening for methicillin-resistant Staphylococcus aureus carriers among patients and health care workers of a tertiary care hospital in south India. Indian J Med Microbiol. 2009;27(1):62-4.

8. Buhlmann M, Bogli-Stuber K, Droz S, Muhlemann K. Rapid screening for carriage of methicillin-resistant Staphylococcus aureus by PCR and associated costs. J Clin Microbiol. 2008;46(7):2151-4.

9. Shittu AO, Lin J. Antimicrobial susceptibility patterns and characterization of clinical isolates of Staphylococcus aureus in KwaZulu-Natal province, South Africa. BMC Infect Dis. 2006;6:125.

10. Brown DF. Detection of methicillin/oxacillin resistance in staphylococci. J Antimicrob Chemother. 2001;48(1):65-70.

11. Schmitz F J, Steiert M, Tichy HV, Hofmann B, Verhoef J, Heinz HP, et al. Typing of methicillin-resistant Staphylococcus aureus isolates from Dusseldorf by six genotypic methods. J Med Microbiol. 1998;47(4):341-51.

12. Salmenlinna S, Vuopio-Varkila J. Recognition of two groups of methicillin-resistant Staphylococcus aureus strains based on epidemiology, antimicrobial susceptibility, hypervariable-region type, and ribotype in Finland.J Clin Microbiol. 2001;39(6):2243-7.

13. Pourmand MR, Abdossamadi Z, Salari MH, Hosseini M. Slime layer formation and the prevalence of mecA and aap genes in Staphylococcus epidermidis isolates. J Infect Dev Ctries. 2011;5(1):34-40.

14. Stranden A, Frei R, Widmer AF. Molecular typing of methicillinresistant Staphylococcus aureus: can PCR replace pulsed-field gel electrophoresis? JClin Microbiol. 2003;41(7):3181-6. 